This item was submitted to Loughborough's Research Repository by the author.

Items in Figshare are protected by copyright, with all rights reserved, unless otherwise indicated.

\title{
A mirror with wings: Photography and the new era of communications
}

\section{PLEASE CITE THE PUBLISHED VERSION}

http://www.psupress.org/books/titles/978-0-271-07916-5.html

\section{PUBLISHER}

Pennsylvania State University Press

\section{VERSION}

AM (Accepted Manuscript)

\section{PUBLISHER STATEMENT}

This work is made available according to the conditions of the Creative Commons Attribution-NonCommercialNoDerivatives 4.0 International (CC BY-NC-ND 4.0) licence. Full details of this licence are available at: https://creativecommons.org/licenses/by-nc-nd/4.0/

\section{LICENCE}

CC BY-NC-ND 4.0

\section{REPOSITORY RECORD}

Natale, Simone. 2019. "A Mirror with Wings: Photography and the New Era of Communications". figshare. https://hdl.handle.net/2134/28348. 


\section{Chapter 2}

\section{A Mirror with Wings: \\ Photography and the New Era of Communications}

\section{Simone Natale}

In 1853, the celebrated trance-writer and prophet of the American spiritualist movement Andrew Jackson Davis compared spirit communication to a kind of telegraphic channelling. In explaining how "spiritual telegraphy" could connect a mother to her son, he mentioned another new technology that had spread in the United States during the previous decade: photography. In Davis' words, “the actual condition of the son is daguerreotyped upon the mother's brain telegraphed, so to speak, or impressed, as perfectly as any object can be painted on the physical organ of sight.” ${ }^{1}$ As he was writing, photography and electric telegraphy were two novel technologies of communication that were largely perceived as revolutionary. Writers, scientists, intellectuals, and even visionary prophets like Davis celebrated their impact and relevance. It made much sense, in such historical moment, to refer to the two media in conjunction with each other, as he did, using the daguerreotype and the telegraph as exchangeable metaphors for spiritual communication.

One and a half century later, much has been lost about that cultural climate. Media historians have explored the nineteenth century as an epoch where new understandings of communication emerged, and the fundamental tenets of today's media culture were established. ${ }^{2}$ Yet, despite the fact that photography was introduced and developed in the same historical period, and notwithstanding the field's purportedly systemic approach to the interactions 
between different media, photography has remained a relatively marginal subject for them, secondary to telegraphy, wireless, sound recording, film, television, and other visual media. Conversely, art historians have, at least until very recently, underestimated the extent to which photography interacted with the new media of communication and transportation of the nineteenth century. ${ }^{3}$

This chapter aims to address these gaps by questioning photography's place in the broader history of nineteenth-century communication media. Focusing on the context of middlenineteenth century United States, I aim to unveil how photography participated in the transformations of how communication was conceived, administered, and used. Firstly, I show that photography is related in several ways to telegraphy, railroads and postal services, some of

the technologies and systems that revolutionized communication in the mid-nineteenth century. ${ }^{4}$ Secondly, I argue that the emergence of photography was informed, as was telegraphy, by a dream of going beyond previous boundaries of space and distance. Photography was conceived as a medium that put images in movement, allowing pictures taken from reality to be carried, marketed and transported. In fact, photography was from the very beginning a medium of communication in the strictest sense of this term. Putting images taken from reality in movement, and allowing them to circulate across space, photography was perceived and used as pertaining to a range of new technologies that were transforming the very functioning and conditions of human communication.

\section{The Telegraph of Art: Mediated Communication around 1839}

As scholars such as Jeffrey Sconce and John Durham Peters have shown, nineteenth-century spiritualism and psychical research were extraordinarily receptive towards innovations in 
communication technology. ${ }^{5}$ It is therefore not surprising that the relationship between photography and other communication media went sometimes acknowledged with greater clarity in occultist and spiritualist writings than in texts produced within other contexts and fields. ${ }^{6}$ An apt example of this dynamics is an article entitled "Facts in Spiritual Science," published in 1854 by a spiritualist periodical. The article mentioned three cases of recently recorded spiritualist phenomena - each having to do with media communications. The first case was set in a railroad car, where Miss Rachel Ellis, a spiritualist medium, was addressed in French by an unknown woman. Despite not knowing this language, the medium found herself uttering words in a strange language, as possessed, entertaining a lengthy conversation despite not having the slightest idea of its content. The second case had to do with the mediated communication of words: the author recounted how a woman communicated with her deceased daughter at a spiritualist séance, where a message from the beyond likened telegraphic exchanges in Morse code, as well as through letters that she locked up in a drawer for delivery to the spirit of her deceased daughter. In the third reported case another new communication medium, the daguerreotype, made its appearance. A picture was given to a medium, who recognized in it the likeness of a man she had seen in the spirit world. As the report underlined, the medium had never seen the man in person, but only through the mediation performed by both photography and spiritual communication. ${ }^{7}$

The insertion, in all the three reported "spiritual facts," of media of transportations and communications such as the railway, the telegraph, the post, and photography, was hardly a coincidence. In opening the article, the author seems to hint at the fact that his piece was on the miracle of spiritualist communication as much as on the new conditions created by transformations in the way communications were exchanged and mediated. He particularly 
stressed the striking novelty of the ways through which spirits manifested themselves.

Demonstrations of the spirits' identity and existence were "often as unexpected as they are singular and convincing"; scarcely a day passed without bearing "some new and striking illustration of Spiritual presence and power." ${ }^{8}$ He lived in a world, after all, where communications travelled through new, unprecedented channels, changing in irreparable ways the perception of distances of time and space. The anecdotes he recounted linked the experience of novel forms of spirit manifestation with that of communication and transportation media. The journey in a railway carriage was the occasion for entering in contact with distant worlds that had until recently been confined to the realm of imagination; telegraphy and the postal system built a connection with loved ones in spite of the separation in space; and the daguerreotype carried images taken from reality, allowing our eyes to see what they had previously not been able to reach.

Although its context of appearance may seem unusual, the article encourages us to look at all these media in concert with each other, rather than in isolation. In this section, I follow this encouragement by pointing to relations between photography and three technological shifts that revolutionized human communications in nineteenth-century America: the introduction of the telegraph; the development of a national railroad system; and the transformation of postal exchange from an apparatus that was used by a limited number of individuals to a network employed by large masses of ordinary Americans.

Despite a striking coincidence of dates - the first public demonstration of telegraphy was in 1838, just one year before the publication of Daguerre's invention; the first telegraphic line was officially opened in 1844 - correlations between the cultural reception of photography and the telegraph have been largely disregarded. Relevant exceptions can be found in essays by 
Geoffrey Batchen and William Uricchio. While Batchen reported some circumstances common to the history of photography and telegraphy, ${ }^{9}$ Uricchio argued that photographic technologies contributed, like communication media, to stimulating a new experience of time, space and event, based on the sharing of "spatial and temporal dimensions that exceed those normally available to human subjects." ${ }^{10}$ As Susan S. Williams noted, from the 1840 s the daguerreotype was often mentioned in the same breath as the telegraph as the supreme examples of the American progress. ${ }^{11}$ Popular publications which gave accounts of the major inventions of the nineteenth century often positioned photography and telegraphy together as protagonists of technological revolution of the nineteenth century. ${ }^{12}$ In 1856, for instance, the Harper's New Monthly Magazine listed among 'the most notable gifts of the United States to the world' the electric telegraph, the art of photography and the discovery of the properties of sulphuric ether when inhaled. ${ }^{13}$

Electricity, on whose power the telegraph was based and which was often presented during the nineteenth century as an omnipotent, quasi-magical force, ${ }^{14}$ was also related to the functioning of photographic technologies. In an early history of the electric telegraph, published in New York in 1852, the author reasoned that electricity was also to be found “in the sun’s rays, and on the surface of Daguerreotype plates, delineating the human features.” ${ }^{15}$ According to Batchen, the attempt to transform electricity into visual form symbolically unified the emergence of photography and telegraphy in the mid-nineteenth century. In July 1838, the Englishman Edward Davy granted a patent for a telegraphic system, in which a current being received was passed through a moving paper tape soaked in potassium iodide, leaving a coloured mark: “electricity was thereby turned into a legible image, a kind of image produced very much like a photograph (automatically, as a chemical reaction to received energy).”16 
Hopes and fears that emerged in connection with the new technologies of telegraphy and photography often overlapped. The innovative nature of photography was sometimes underlined by mentioning its relations to communication and transportation technologies: for instance, the Philadelphia Photographer in 1866 labelled photography "the railway and telegraph of art,” observing that it too was also able to "carry us to points afar." ${ }^{17}$ Common associations between the daguerreotype and telegraphy also concerned the risks connected with abuses of these technologies. Thus, in an article that expressed concern for the production of duplicates of works of art, the London magazine The Athenaeum observed that the daguerreotype was "almost equally active in the forgery of property [as] the telegraph in the forgery of news.” In this age of fakery and forgery, the art collector required a constant watchfulness and accurate knowledge, "as it requires a large intelligence to interpret the wayward and fantastic communications of the electric telegraph.”18

Another point of contact in the early development of telegraphy and photography is to be found in the acquaintance with photographic technologies of Samuel F. B. Morse, the main contributor to the introduction of the electric telegraph in the United States. Morse, who may have fantasized about inventing a photographic system as early as $1821,{ }^{19}$ met Daguerre in Paris in 1839. At this meeting, Daguerre and Morse agreed to demonstrate to each other the wonders of their respective inventions. Morse was also the author of the first recorded reaction to Daguerre's invention by an American, publishing a letter in the New York Observer on 20 April 1839. ${ }^{20}$ He became one of the pioneers of the daguerreotype in the United States, opening a portrait studio in association with J.W. Draper in New York in 1840 (fig. 2.1).

$<$ Insert figure 2.1 here $>$ 
The influence of the railroad on nineteenth-century photography and visual culture has been discussed by several authors, most famously the German cultural historian Wolfgang Schivelbusch. He argues that railway journeys stimulated the emergence of a new kind of visual perception: the spectacle of the landscape in movement allowed passengers of trains to experience a form of "panoramic travel.”21 But the relationship between the railroad and photography was not limited to the representation of landscape and movement. The first two decades after Daguerre’s invention were characterized by improvements in both photographic and transportation technologies. In several cases, the railroad and the daguerreotype came to be strategically allied. Reportedly, for instance, the opening of the railroad in Belgian town of Courtrai was to be greeted through a particular application of the daguerreotype:

The camera obscura is to be placed on an eminence commanding the royal pavilion, - the locomotive engine, the train of wagons, and the major part of the cortège, and is to be brought into action exactly at the time of the delivery of the inauguration speech. A discharge of cannon is to be the signal for a general immobility, which is to last the seven minutes necessary for obtaining a good representation of all the personages present. The plate is afterwards to be enclosed in lead and deposited under the first stone of the foundation of the station at Courtrai. ${ }^{22}$

Both railway and photography "were new technologies that lent themselves to the projects of media governance and nation-building." 23 In nineteenth-century America, photography and the railway became symbolic protagonists of the conquest of the Western frontier. ${ }^{24}$ As Anne M. Lyden has pointed out, "nowhere else on earth did railroads and photography advance so completely side by side, mutually reinforcing each other." ${ }^{25}$ The first of the four surveys of continental lands planned in the late 1860s by the American Department of 
War, led by geologist Clarence King and including professional photographers of the calibre of Timothy H. O’Sullivan and Carleton Watkins, was conceived as part of a programme of economic expansion alongside the transcontinental railroad system (fig. 2.2). ${ }^{26}$

$<$ Insert figure 2.2 here $>$

Not only the federal government, but also railroad companies contributed to the connection between photography and the train, commissioning photographers to document the natural attractions and the towns springing up along the new routes. In this context, photographic images were seen as an opportunity to attract financial support and to tempt passengers to travel to the destinations now accessible by train. ${ }^{27}$ Furthermore, the railroad was among the favourite subjects of nineteenth-century American landscape photographers. In an essay about the artistic representation of the railway, Leo Marx has argued that the representation of the railroad expressed "a heightened sense of change itself — its accelerating pace and its potentially allencompassing scope.”28 In this sense, no other means of representation could represent the railway better than the new mechanical imaging of photography.

The emergence of photography has also something to share with the increase in postal exchange that followed the introduction of cheap postage in nineteenth-century America. Although mail delivery is much older than the telegraph, it was only in the middle of the nineteenth century that ordinary Americans began participating in a regular network of longdistance communication. Through substantial reductions in the cost of postage, the American Congress stimulated during this period "a communications revolution that was as profound in its consequences for American public life as the subsequent revolutions that have come to be associated with the telegraph, the telephone, and the computer." ${ }^{29}$ Between 1840 and 1860, the number of letters carried annually by the US post office increased from about 27 million to about 
161 million, leading to the emergence of a new perception of access to postal services, which started to be described as one of the fundamental conditions of modern life. ${ }^{30}$

Despite some notable exceptions, ${ }^{31}$ historians of photography have largely ignored the connections between early photography and postal services. Yet, as David M. Henkin rightly underlines, the roughly contemporaneous emergence of daguerreotype portraiture and cheap postage is striking. ${ }^{32}$ After the 1845 reform of American postal services, the cost of adding a daguerreotype to a letter was reduced to nothing, and photographic portraits could travel free throughout the United States. Dead letter inventories of the time demonstrate that daguerreotypes and later photographs on paper had become a staple item of postal exchange as early as at the end of the 1840s.

Sent by post, the photograph was, like the autograph letter, a mode of representing absent persons. The symbolic relevance of sending one's portrait to relatives and friends has probably been underestimated in the historical examination of photography's early cultural reception. Photography made everyone's image easily transportable, allowing masses of Americans to enjoy an imaginary contact with distant others. The circulation of photographic portraits by post was further increased by events such as the Civil War and the California gold rush, which took hundreds of thousands of Americans away from their homes for long periods of time. Postal communication was their primary link with their disconnected families. Photography also played a role in strengthening such contacts. In fact, as Henkin has suggested, in cases such as that of a Iowan J. H. Williams receiving the photography of a son could be such a powerful form of symbolic contact that it came to be considered "as good as a short visit." 33

The popularization of the postal system also had a strong impact in business. Items sold per correspondence included photographic materials, thereby facilitating the diffusion of 
photography throughout the States. As an advertisement for the selling of photographic chemicals and materials pointed out, "the facilities of intercourse by mail, rail-road and telegraph are now so speedy and sure, that all have the privilege of trading in the city, at city prices.”34 Professional photographers used the mail to extend the reach of their art and commerce. William Mumler, a spiritualist portrait photographer who offered to his customers portraits enriched by the presence of superimposed figures that were allegedly spirits of the dead, employed the mail to reach customers from distant spiritualist communities; the same strategy was employed by other spirit photographers. ${ }^{35}$ Cartes de visite of famous personalities were likewise commercialized per post, playing an important role in the establishment of a seminal celebrity culture in the nineteenth century. ${ }^{36}$ The postal system was also instrumental in bringing together networks of amateurs dispersed in space. One notable example is the Postal Photographic Club, founded by C.W. Canfield and E.L. French of Aurora, New York, which was designed to educate amateurs in rural areas. ${ }^{37}$

In the middle nineteenth century, the introduction of photography coupled with a range of contemporary transformations in communications, from the telegraph to the railway and the postal system. In what sense, however, did photography challenge the ways communication was performed? Which is photography's place in the burgeoning media culture of the nineteenth century? As the next section shows, the examination of Oliver Wendell Holmes' classic essays on photography may provide us with key insights to answer these questions.

\section{Communicating the Image: Photography and the Annihilation of Space}

In 1861 Oliver Wendell Holmes published the second of his three essays on photography in the Atlantic Monthly. After discussing photography’s innovative character, Holmes invited his 
readers to "a brief stereographic trip, - describing, not from places, but from the photographic pictures of them which we have in our own collection'. ${ }^{38}$ From the Niagara Falls to Broadway, from the Dead Sea to the pyramids, the reader was carried in an imaginary journey around the world, realised by means of stereoscopic photography. Recalling another common narrative of his time, that pointing to the annihilation of space realized by transportation technologies, such as the railroad and the steamboat, and by the new electrical communication media, such as the telegraph, Holmes framed photography in a world where traditional boundaries of distance were becoming increasingly out-to-date - and large catalogues of distant places and locations was made available to the viewer by a burgeoning stereographic industry.

Notwithstanding the fascination of such imaginary journey with the stereoscope, the most frequently cited among Holmes's essays on photography is not that describing the 'photographic trip' but rather his first one, published in the Atlantic Monthly in 1859, where he famously termed photography "the mirror with memory." 39 This metaphor is usually invoked as evidence of photography's capacity to deceive time, memorizing on the plate's surface a vision that would appear only momentarily on a mirror. Less attention is given, however, to the fact that in his 1859 essay Holmes also stressed photography's power to defeat not just time, but also space. A few pages after his reference to the "mirror with memory," Holmes depicted stereoscopic photography as "a universal currency of these banknotes, or promises to pay in solid substance, which the sun has engraved for the great Bank of Nature." ${ }^{40}$ A photograph, according to Holmes, stands in relation to its referent in the same way as banknotes stand to the monetary value inscribed on them. Interpretations of this argument have been various. Alan Trachtenberg considered this to refer to the uncertain status of money, and hence of representation, in antebellum America. ${ }^{41}$ Nancy M. West, on the other hand, claimed that Holmes intended to hint 
at the status of capitalism production. ${ }^{42}$ In line with authors such as Martha Sandweiss and Miles Orvell, I point to another interpretation: what banknotes and photographs had in common was their capacity to transform matter into paper notes that were easily exchanged and moved. ${ }^{43}$

The primary aim of money is to circulate within the market, to become a universal form of exchange that can be readily carried and transferred. ${ }^{44}$ Like banknotes, photographs allowed viewers to make images circulate. In this sense, photography has in common with the new communication media that it went beyond existing barriers of distance. "By making a sheet of paper reflect images like a mirror and hold them as a picture,”45 as Holmes put it, photography transformed reality into an easy-to-handle commodity that could be carried, marketed and sent to distant locations. While engravings and other forms of graphic media put images in circulation well before the invention of photography, a new industry for photographic reproductions strongly enhanced this process, bringing viewers in contact with images that had been taken from reality in countless sites around the world.

In Holmes’ essay, the idea that images are commodities with their own commercial value is central. Stereoscopic photography, to which Holmes's essay was dedicated, was one of the first photographic forms to be produced and commercialised as an industrial commodity. ${ }^{46}$ Originally conceived as an optical device designed to illustrate a theory on vision, the stereoscope was transformed into a widely popular amusement since the 1850s, when it was applied to photography to give a three-dimensional effect. With a production that allowed the stereographic industry to publish, from the mid-nineteenth century to the 1930s, between three to six million different images, stereoscopic photographs can be considered the first mass visual medium. ${ }^{47}$ The stereoscope became the dominant visual mode in which images of distant places and journeys were recollected or imagined. The circulation of images reproducing the most 
famous sights of the world, converted into spectacle by the photographer, could now be purchased and viewed by Americans and Europeans in the comfort of their houses (fig. 2.3). ${ }^{48}$ Something similar was achieved also through magic lantern slides by which photographic projections of distant locations were made available to wide audiences around the world. $<$ Insert figure 2.3 here $>$

The relationship between photography and the circulation of commodities was recalled in an article that appeared in the magazine Littell's Living Age in 1854. The author of this piece enthusiastically mentioned the possible applications of photography to aid travelling salesmen in promoting their wares: instead of travelling to an open market to buy goods, a travelling salesman could now bring a picture of those goods to one's own home. ${ }^{49}$ A context in which photography's capacity to circulate becomes particularly evident is photographic jewellery. Lockets and other objects that incorporated photographs were extremely common during the nineteenth century. In this context, photography was transformed through the inclusion to part of the wearer's body. As Geoffrey Batchen noted in an essay dedicated to vernacular photography, "this is photography literally put in motion, sharing the folds, volumes, and movements of the wearer." ${ }^{50}$ Another interesting example of the inclusion of photography in a commercial commodity of wide circulation is a brand of cigarette card produced by the Ogden tobacco company, featuring 8,000 picture cards that promised to offer a "panorama of the world at large." 51

The exchange of daguerreotypes and other photographic images in the rising postal system of nineteenth-century America, discussed at the end of the previous section, also supports this interpretation of Holmes’s comparison between photography and banknotes. David M. Henkin documented that photographs and money were among the most popular items of postal 
exchange in the mid-nineteenth century. ${ }^{52}$ This is easily explainable by recalling the fact that both items could be conveniently attached to a letter, allowing a form of payment or economical support at distance in one case, a visual connection between distant persons in the other.

As these examples show, the mobility of pictures and other photographic items was embedded in photography's material character. ${ }^{53}$ As material objects, photographs are able to circulate and to challenge distances of space. Jennifer Roberts has recently argued that, before the telegraph, portability and communicability were synonymous, while after the introduction of electrical communication words became faster and pictures were literally "left behind -their stubborn materiality and specific visuality crystallized by their recalcitrance to electronic translation." ${ }^{54}$ Yet, as Roberts aptly notes, the immateriality of telegraphic transmission also made the materiality of visual configurations more viable, adding new emphasis on how photographs and other artworks were moved and transported across space. The materiality of photographs, in fact, was responsible for binding them to the limitations of space as well as for their capacity to outdo such limitations, moving across the United States and the world. ${ }^{55}$ The same applies to the containers where they were placed and to the different supports that made up their materiality: a history of photography's mobility is also a history of boxes, albums, frames, and photographic supports. ${ }^{56}$

Since the first experimentations with this new technology, the instantaneity of transmission was heralded as the main achievement of electric telegraphy. ${ }^{57}$ In contrast, early photography was a lengthy process, one that could require seconds or even minutes of exposure for an image to be taken. Yet, the rapidity by which photographic pictures could be taken and developed was striking, if compared with painting and drawing. Commentators stressed that photography created in the span of just a few seconds something that required an accomplished 
artists several days of work - a rapidity of execution that could not be equated by any other medium to produce pictures. ${ }^{58}$ The "wonderful rapidity of photographic action” was saluted as one of the qualities that maximized photography's impact in the realms of science, industry, and art. $^{59}$ Additionally, by making it possible to visualize two places at the same time, photography also created the illusion of synchronicity and disembodied presence, two effects that characterized the impact of electrical communications as well. ${ }^{60}$ The possibility of electronic and photographic presence allowed for the establishment of communication links that, as argued by John Durham Peters, were conceptualized as empathic connections with distant others. ${ }^{61}$ In fact, historians of photography have frequently stressed how photographic portraits contributed to the establishment of emotional links between people separated in space; recently, media scholars interested in the history of emotions have showed that something similar also shaped the early reception of electric telegraphy. ${ }^{62}$

Photography's challenge to the boundaries of space and distance in the nineteenth century is further testified by its immediate application to travel. Travel and tourism were part of the arguments in favour not only of the railway but also of photography. ${ }^{63}$ The dream of travelling to the most distant and exotic destinations in the world by means of photographs or stereoscopic cards was evoked by many commentators of the time. An article in The Photographic Journal, for instance, suggested that photography "brings to us in the cheapest and most portable form, not only the picture, but the model, in a tangible shape, of all that exist in the various countries of the globe [...]. By our fireside we have the advantage of examining them, without being exposed to the fatigue, privation, and risks of the daring and enterprising artists who, for our gratification and instruction, have traversed lands and seas." ${ }^{64}$ As Joan Schwartz points out, at the same time when the railway and the steamship made the world more accessible at a physical level, 
photographic technologies made it visually more accessible: "the photograph became a surrogate for travel at a time when travel was the premier avenue to knowledge of the world.”65

The practical and symbolic relevance of circulation, exchange and travelling in the acceptance and practical use of photography, suggests that photography contributed in the nineteenth century not just to a shift in the techniques of representations, but to the broader development of novel forms of mediated communication that characterized the age of electrical communications. By rendering the image easily transportable or, in other words, by transforming the real into banknotes, photography demands its room in that annihilation of previous boundaries of space that is usually connected to the development of telegraphy, railroads and modern postal services in nineteenth-century America. The era of modern communication, whose beginnings is often identified by media historians with the emergence of electrical telegraphy, was also the era of photography. To paraphrase Holmes’s words, the new photographic medium was not only a mirror with memory, but also, and perhaps especially, a mirror with wings.

\section{Endnotes}

A shorter and much different version of this text was previously published as Simone Natale, "Photography and Communication Media in the Nineteenth Century,” History of Photography 36, no. 3 (2012): 451-56.

${ }^{1}$ Davis, The Present Age, 194.

${ }^{2}$ See, among many others, Gitelman, Scripts, Grooves, and Writing Machines; Otis, Networking; Kittler, Discourse Networks; Flichy, Dynamics of Modern Communication; Marvin, When Old Technologies Were New. 
${ }^{3}$ This gap has recently started to be addressed by a growing body of literature addressing photography in relationship to the history of other media. See in particular Taws, "When I Was a Telegrapher"; Roberts, Transporting Visions; Hill and Schwartz, eds., Getting the Picture. ${ }^{4}$ While one might argue that railroad was a technology of transportation rather than communication, it is important to note that the term communication and transportation were virtually synonymous in the nineteenth century. The history of the railway is inseparable from the history of telecommunications: telegraphy, for instance, was instrumental in the organization and functioning of railway networks; also, the kind of cheap and rapid postal system that emerged in the first half of the nineteenth century would have been unthinkable without the railway. See, in this regard, Czitrom, Media and the American Mind.

${ }^{5}$ Sconce, Haunted Media; Peters, Speaking into the Air.

${ }^{6}$ The history of occult beliefs and psychical research -a realm constitutionally open to extraordinary connections and influences - frequently invites associations between historical events and phenomena that are usually regarded as distinct. This is certainly the case of the association between photography and other media; see, for instance, my examination of the close connections between $\mathrm{X}$ rays and wireless telegraphy in psychical research at the end of the nineteenth century. Natale, "A Cosmology of Invisible Fluids."

${ }^{7}$ Brittan, "Facts in Spiritual Science."

${ }^{8}$ Brittan, "Facts in Spiritual Science," 7.

${ }^{9}$ Batchen, "Electricity Made Visible."

${ }^{10}$ Uricchio, "Ways of Seeing," 123. For other, more recent attempts to link photography and telegraphy, see Taws, "When I was a Telegrapher"; Roberts, Transporting Visions.

${ }^{11}$ Williams, "The Inconstant Daguerreotype," 166. 
${ }^{12}$ See, for instance, Iles, Flame, Electricity; Laxton, "Electric Telegraphs," 9.

13 "Editor's Table," 411.

${ }^{14}$ Morus, Frankenstein's Children.

${ }^{15}$ Jones, Historical Sketch, v.

${ }^{16}$ Batchen, "Electricity Made Visible," 36.

${ }^{17}$ Quoted in Lyden, Railroad Vision, 4.

18 "Our Weekly Gossip," 312.

${ }^{19}$ Batchen, "Electricity Made Visible," 37. It is important to note that Morse was, beside an inventor of electrical devices, a very famous painter; in his career, the trajectories of communication and visual media converge with particular clarity.

20 Trachtenberg, Reading American Photographs, 15.

${ }^{21}$ Schivelbusch, The Railway Journey.

22 "The Daguerreotype."

${ }^{23}$ Foster, "Capturing and Losing," 141.

${ }^{24}$ Leonardi, Il paesaggio americano.

${ }^{25}$ Lyden, Railroad Vision, xii.

${ }^{26}$ Trachtenberg, Reading American Photographs, 123-24.

${ }^{27}$ Lyden, Railroad Vision, 4.

${ }^{28}$ Marx, "The Railroad-in-the-Landscape," 185.

${ }^{29}$ John, Spreading the News, vii.

${ }^{30}$ Henkin, The Postal Age, 2. 
${ }^{31}$ For instance, Alison Morrison-Low has discussed how communication between the pioneers of photography Henry Fox Talbot and David Brewster was facilitated by the improvements in the British postal system. Morrison-Low, "Brewster." See also Smith, Disciples of Light.

${ }^{32}$ Henkin, The Postal Age, 59. See also Chapter 3 of this book.

${ }^{33}$ Henkin, The Postal Age, 57.

${ }^{34}$ Seely, "To Photographers and Daguerreotypists."

${ }^{35}$ See Natale, Supernatural Entertainments, 135-168.

${ }^{36}$ Browne, "Looking at Darwin; Di Bello, "Elizabeth Thompson."

${ }^{37}$ Greenough, "Of Charming Glens," 271-72.

${ }^{38}$ Holmes, "Sun-Painting."

${ }^{39}$ Holmes, "The Stereoscope and Stereograph," 738.

${ }^{40}$ Holmes, "The Stereoscope and Stereograph," 747.

${ }^{41}$ Trachtenberg, Reading American Photographs, 19.

${ }^{42}$ West, "Fantasy, Photography, and the Marketplace."

${ }^{43}$ Sandweiss, Photography in Nineteenth-Century America, 42-43; Orvell, The Real Thing.

${ }^{44}$ On the relationship between money and artistic representation, see Shell, Art \& money.

${ }^{45}$ Holmes, "The Stereoscope and Stereograph," 738.

${ }^{46}$ McCauley, Industrial Madness; Plunkett, "Selling Stereoscopy."

${ }^{47}$ Babbitts, "Stereographs," 129.

${ }^{48}$ Strain, "Exotic Bodies," 76.

49 "Busy with Photographs."

${ }^{50}$ Batchen, Each Wild Idea, 66.

${ }^{51}$ Strain, "Exotic Bodies," 76. 
52 The Postal Age, 9.

${ }^{53}$ Edwards and Hart, eds., Photographs Objects.

${ }^{54}$ Roberts, Transporting Visions, 6.

${ }^{55}$ Edwards, "Material Beings."

${ }^{56}$ See Edwards and Hart, "Mixed Box." Photography’s capacity to defeat time is also grounded on its materiality. See in this regard Nicholas Yablon's study of early time capsules from the end of the nineteenth century. Yablon, "Posing for Posterity."

${ }^{57}$ Morus, "The Nervous System."

${ }^{58}$ Munro, "The Optical Stranger," 172-73.

59 "Wonderful Rapidity."

${ }^{60}$ Schwartz, "Records of Simple Truth," 21-22. On the concept of electronic presence and disembodiment, see Sconce, Haunted Media.

${ }^{61}$ Peters, Speaking into the Air.

62 This became particularly evident when the telegraphic link broke down and messages failed to be delivered. Malin, "Failed Transmissions."

${ }^{63}$ See, among others, Schwartz and Ryan, Picturing Place; Hoelscher, "The Photographic Construction.".

${ }^{64}$ Claudet, "Photography," 266. Emphasis mine.

${ }^{65}$ Schwartz, "Records of Simple Truth," 14. 